\title{
RFID-Based Digital Door Locking System
}

\author{
Shubham Soni, Rajni Soni, Akhilesh A. Waoo
}

\begin{abstract}
This is an IoT-enabled RFID-based door locking gadget. This door lock system will know how long the door is open and in this door lock system, only those people who register will be able to enter using their card. It uses a servo motor that operates with the help of Arduino. The Arduino board runs with complete programming that is stored inside it. By using this gadget, an owner can track his office and the place where he wants to let the specific people in. It is also very secure. RFID Module, LCD Display Red and Green and Yellow LED Light and Buzzer have also been used in this door lock system. When the door is locked, the yellow LED will be on and when the door lock is open, the green led light will turn on. The Red LED work will alert you that your card is wrong.
\end{abstract}

Keywords: Arduino, Buzzer, Door Lock System, IoT, LED, LCD, Microcontroller, RFID.

\section{INTRODUCTION}

This gadget is designed with the help of an Arduino using a servo motor that pushes the gear forward and back. When we scan our register card, there is a loop start of store programming in which the servo motor rotates 90 degrees, then the gear mechanism in it works, which locks and opens the lock. In simple language, when a card is scanned, the condition given in the programming matches, then the command given in that condition becomes active, such that when the correct card is scanned, the open condition will match, in which the servo motor will rotate 90 degrees and The green light will be on and the buzzer will beep for 500 microseconds and the door lock will be open but when an unregistered card is scanned then the condition of the wrong card will match which will beep twice for 500 microseconds and the red light will be on for 1 second. The Wrong card will show on the LCD.

\section{LITERATURE REVIEW}

By using Arduino [6] automatic RFID-based access control system was designed this system represents a combination of RFID system and order no to achieve a particular task. RF reader detects an RFID tag then the system captures the UID that is a unique identifier.

Manuscript received on 31 May 2021 | Revised Manuscript received on 13 July 2021 | Manuscript Accepted on 15 September 2021 | Manuscript published on 30 September 2021.

* Correspondence Author

Shubham Soni, Student, Department of Computer Science and Engineering, AKS University, Satna, MP, India

Rajni Soni, Student, Department of Computer Science and Engineering, AKS University, Satna, MP, India

Akhilesh A. Waoo*, Associate Professor and Head, Department of Computer Science and Engineering, AKS University, Satna, MP, India

(C) The Authors. Published by Lattice Science Publication (LSP). This is an open access article under the CC-BY-NC-ND license (http://creativecommons.org/licenses/by-nc-nd/4.0/)
It also captures the user's image which then scans and compares with the database for matching. If card UID matches with capture image then access is granted or access is denied and the system gives an alert alarm for security purposes this system plays a significant task of entrance monitoring controller and exit monitoring controller it can be installed at the entrance and exit gate [1]. This system can be used in hostels for security purposes. In this technology, response time can be e enhanced by using controller processes and real-time images. Umar et al suggested and developed an RFID-based security control system and also installed it in hostels at the Punjab University campus this system combines RFID technology with biometrics [8].

RFID is Radio Frequency Identification which is a fundamental and cheapest technology to enables wireless data transmission [2]. Radio frequency Identification i.e., RFID is a non-contact technique applied in industries for personal tracking, supply chain management, management of books in libraries and at tollgate [3]. RFID technology has a lack of standardization and hence it has not been very often among the manufacturing companies earlier [4]. RFID technologies are more proficient and more secure as compare to other networks [5]. RFID technology is used in many areas such as public transport, industrial automation, animal identification, ticketing, inventory detection, electronic immobilization, access control, asset and people tracking, and many more [7]. Gyanendra and Pawan [9] proposed a security system using a passive type of RFID contains a door locking system using an actuator.

\section{METHODOLOGY}

The system is composed of three major modules. The microcontroller module consists of the Arduino Uno R3 microcontroller. The RFID module serves as the input of the microcontroller, as the registered card required to open the door must be scanned into the system through the module. The gear mechanism module controls the mechanical action (opening and closing) of the door. It includes a servo motor.

The mechanism of this door lock system makes is explained in figure 1 . There are main four processes by which this gadget works. These four blocks are namely RFID Scanner, Microcontroller, Servo Motor, and Mechanical Door. First, the RFID tag will be scanned by RFID scanner, then the command will go to the microcontroller, The microcontroller will check that if the card is registered or not, then the command will go to the servo motor, according to which programming the servo motor will be rotated $90^{\circ}$ so that the mechanical door lock will work.

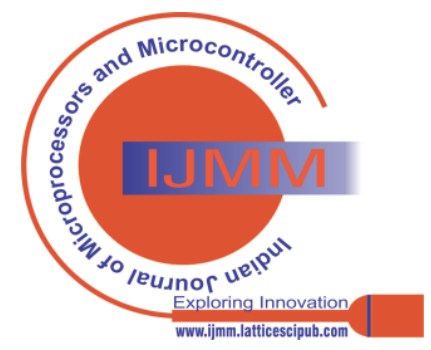




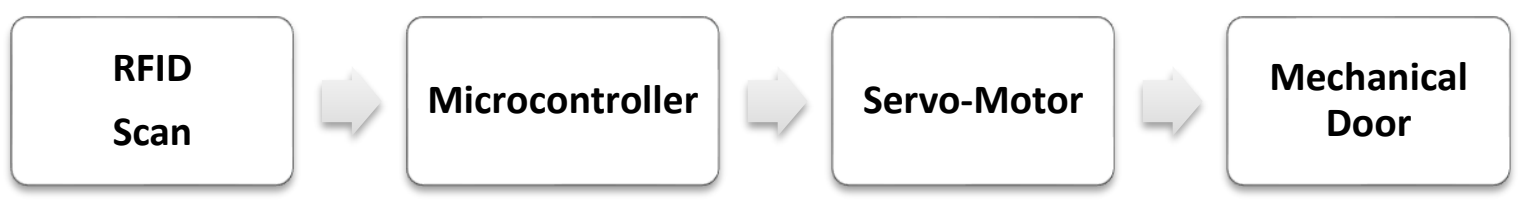

Figure 1: Mechanism of Door Lock System

The automatic door lock system circuit diagram using an Arduino is shown in Figure 2. This circuit is mainly used for an interfacing RFID reader with an Arduino. This project can be enhanced by connecting an LCD to display the outputs.

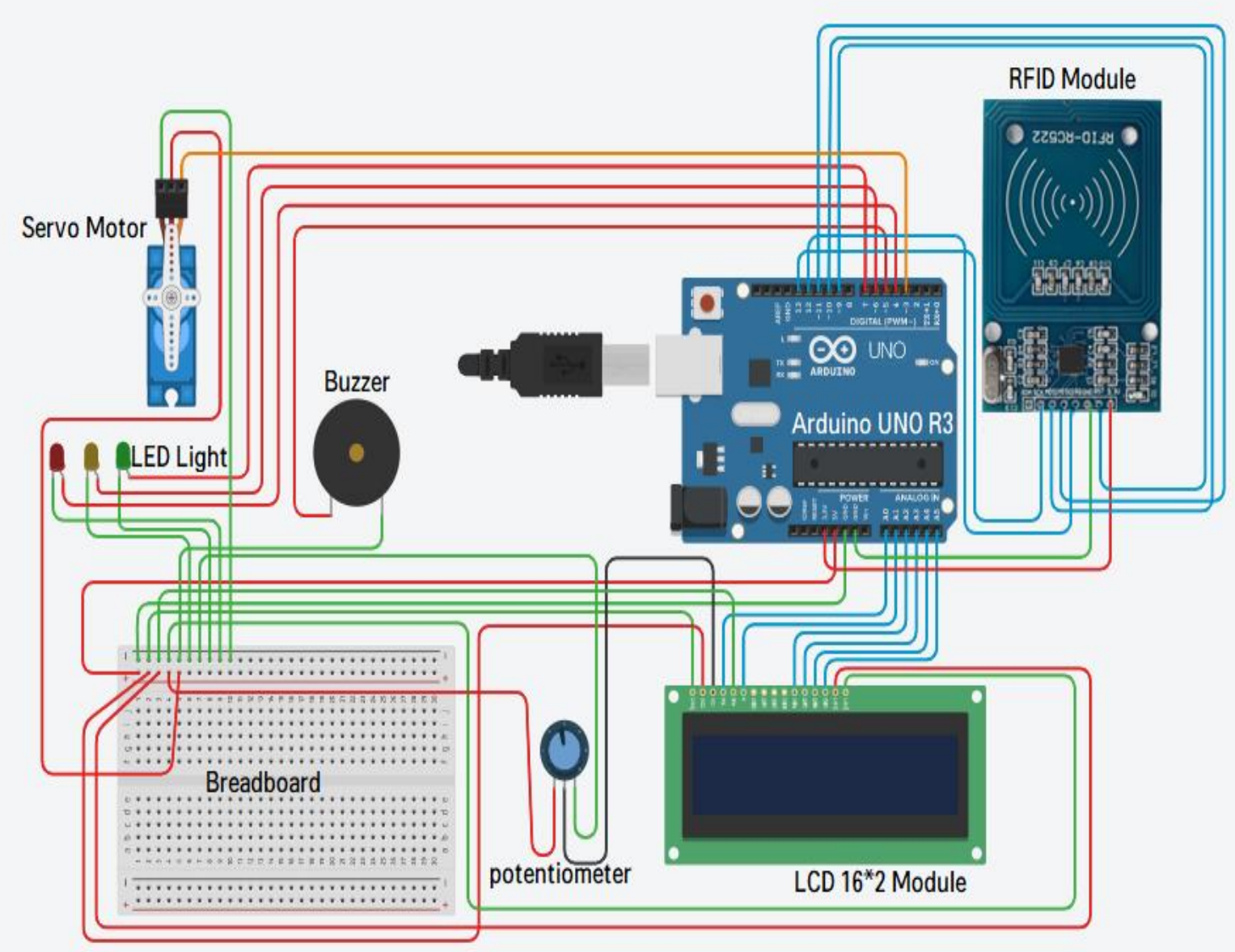

Figure 2: Circuit Diagram of Door Lock System

The circuit of this project uses three separate parts, namely a reader, a controller, and a mechanical door lock. In this circuit, a reader reads the RFID tags, a controller is used to accept the data from the RFID reader and control the output of the door lock and RED, GREEN, YELLOW LED. When the door lock is placed on a door and tested with a battery to check the installation. In many cases, we need a simple circuit on the door lock, which means the automatic door stops locked when there is no flow of current. When 12 volts DC is supplied through the electromagnet in the door lock system, a plate in the door lock offers a way to permit the door to be pushed open easily. Table 1 shows the hardware details and its working.

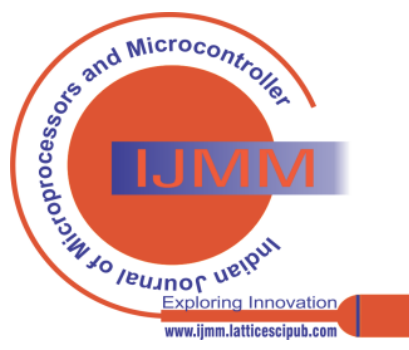


Table 1: Hardware Details and Working

\begin{tabular}{|c|c|c|}
\hline Part Name & Quantity & Details \\
\hline $\begin{array}{l}\text { Arduino Uno R3 } \\
\text { microcontroller }\end{array}$ & $1 \mathrm{pc}$ & $\begin{array}{l}\text { The Arduino Uno R3 is a microcontroller board based on a } \\
\text { removable, dual-inline-package (DIP) ATmega328 AVR } \\
\text { microcontroller. It has } 20 \text { digital input/output pins (of which } 6 \text { can } \\
\text { be used as PWM outputs and } 6 \text { can be used as analog inputs) }\end{array}$ \\
\hline Servo Motor & $1 \mathrm{pc}$ & $\begin{array}{l}\text { The servo motor is a closed-loop mechanism that incorporates } \\
\text { positional feedback to control the rotational or linear speed and } \\
\text { position. The motor is controlled with an electric signal, either } \\
\text { analog or digital, which determines the amount of movement } \\
\text { which represents the final command position for the shaft. }\end{array}$ \\
\hline $\begin{array}{ll}\text { RFID } & \text { Module } \\
\text { (MFRC522) } & \end{array}$ & $1 \mathrm{pc}$ & $\begin{array}{l}\text { The RFID module is primarily used for object identification and } \\
\text { tracking. Its abbreviation stands for Radio Frequency } \\
\text { Identification Module. Its working is mostly wireless and uses } \\
\text { electromagnetic fields. }\end{array}$ \\
\hline LCD Display 16*2 & $1 \mathrm{pc}$ & $\begin{array}{l}\text { A } 16 x 2 \text { LCD means it can display } 16 \text { characters per line and there } \\
\text { are } 2 \text { such lines. In this LCD each character is displayed in a } 5 \times 7 \\
\text { pixel matrix. The } 16 \times 2 \text { intelligent alphanumeric dot matrix } \\
\text { display is capable of displaying } 224 \text { different characters and } \\
\text { symbols. This LCD has two registers, namely, Command and } \\
\text { Data. }\end{array}$ \\
\hline Resistors $(10 \mathrm{k} \Omega$ ) & $3 \mathrm{pc}$ & $\begin{array}{l}\text { The } 10 \mathrm{k} \text { resistor provides up to } 500 \mathrm{uA} \text { to overcome any radiated } \\
\text { energy from the environment. }\end{array}$ \\
\hline $\begin{array}{l}\text { Red, Green, Yellow } \\
\text { LED Light Diode }\end{array}$ & $1,1,1$ рс & $\begin{array}{l}\text { A light-releasing diode is an electric component that emits light } \\
\text { when the electric current flows through it. }\end{array}$ \\
\hline Potentiometer & $1 \mathrm{pc}$ & $\begin{array}{l}\text { Potentiometers work by varying the position of a sliding contact } \\
\text { across a uniform resistance. }\end{array}$ \\
\hline Breadboard & $1 \mathrm{pc}$ & $\begin{array}{l}\text { The purpose of the breadboard is to make quick electrical } \\
\text { connections between components- like resistors, LEDs, } \\
\text { capacitors, etc- so that you can test your circuit before } \\
\text { permanently soldering it together. }\end{array}$ \\
\hline Buzzer & $1 \mathrm{pc}$ & $\begin{array}{l}\text { An Arduino buzzer is also called a piezo buzzer. It is a tiny } \\
\text { speaker that you can connect directly to an Arduino. You can } \\
\text { make it sound a tone at a frequency you set. }\end{array}$ \\
\hline
\end{tabular}

\section{Working Method}

Firstly, the door lock system will start, and the scanning process occurs, if the card is registered previously then the command will proceed otherwise the WRONG CARD message appeared with the Red LED blinks 2 times in 1 second and buzzer 2 times in 1 second and again the command scanning process will start, If the card is registered, the Red LED will be blink once for only 500 microseconds and buzzer beeps 1 time for 500 microseconds and the command will execute into the mechanical door lock system and the door lock will be open. When the door lock is open, the command will run again and the scanning process starts, but now the door lock will be closed. The flow chart of the working method is explained in Figure 3.

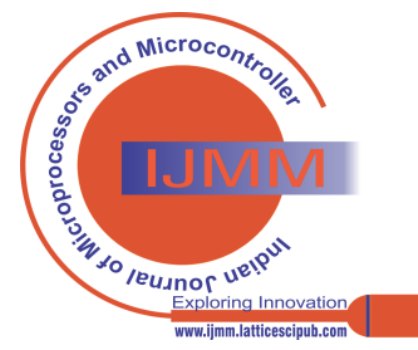




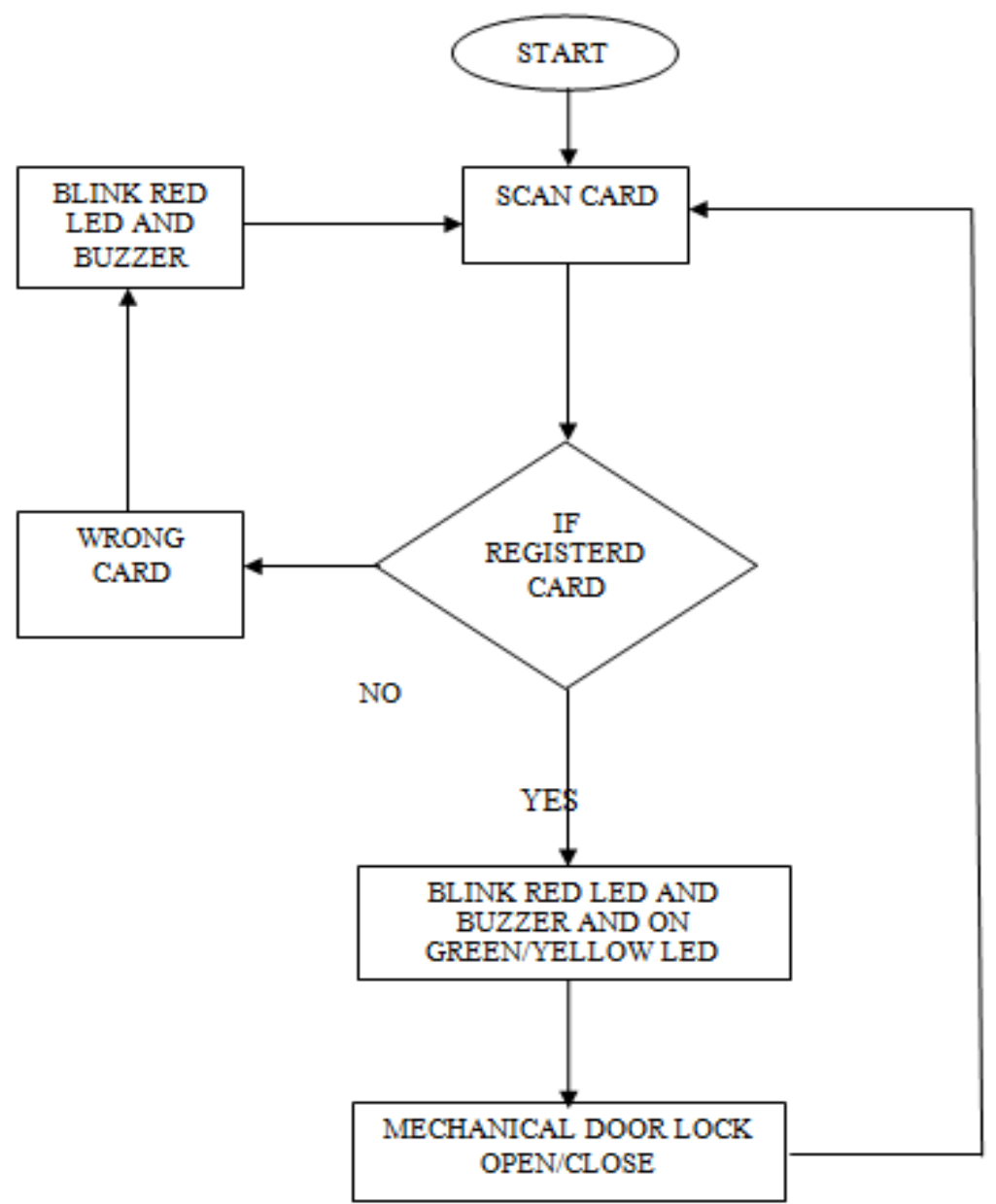

Figure 3: Flow Chart of Working Method

\section{RESULT AND DISCUSSION}

It is an IoT-based gadget designed for RFID-based door locking systems, developed with the help of Arduino. This gadget is being managed by software programming. Let us see how this door lock system works. A 12-volt power adapter is used for the power supply and can also use a 9-volt battery instead of a power adapter. As can see on the screen, it is displaying welcome to my home, if scan any card which is unregistered it shows the wrong card, and the lock is locked. If scanning the registered card, it opens the door lock. And now scan the registered card again, the lock is locked.

\section{CONCLUSION}

The use of the Arduino UNO microcontroller in this project allows design simplicity, therefore, the project can be achieved in a shorter time than other technologies previously employed. And this door lock system is also very secure and saves the information of people coming and going.

\section{REFERENCES}

1. Orji EZ, Oleka CV, Nduanya UI, Automatic Access Control System using Arduino and RFID, Journal of Scientific and Engineering Research, 2018, 5(4):333-340 ISSN: 2394-2630.

2. Zeydin Pala and Nihat Inan, "Smart parking application using RFID technology", RFID Eurasia, 1st Annual in RFID Eurasia, 2007.

3. Dejan Nedelkovski, (2017), "How RFID Works and How To Make an Arduino based RFID Door Lock" Arduino Tutorials - How To Mechatronics", Retrieved 29 May 2021, from http://howtomechatronics.com/tutorials/arduino/rfid-works-makearduino-based-rfid-door-lock.

4. Zhang, L., "An Improved Approach to Security and Privacy of RFID application System", Wireless Communications, Networking and Mobile Computing. International Conference. pp 1195- 1198, 2005.

5. Xiao, Y., Yu, S., Wu, K., Ni, Q., Janecek., C., Nordstad, J,” Radio frequency identification: technologies, applications, and research issues" Wiley Journal of Wireless Communications and Mobile Computing, Vol 7, May 2007. [CrossRef]

6. Website Reference: https://www.arduino.cc

7. Ramalatha, M., Ramkumar, A. K., Selvaraj, S. and Suriyakanth, S, (2014), "RFID Based Personal Medical Data card for Toll Automation". Elysium Journal Engineering Research and Management. Volume1, ISSN: 2347-4408, pp 51-52.

8. Umar Farooq, Mahmood ul Hasan, Muhammad Amar, Athar Hanif, and Muhammad Usman Asad, (2014), "RFID Based Security and Access Control System" IACSIT International Journal of Engineering and Technology, Vol. 6, No. 4, August 2014. [CrossRef]

9. Gyanendra K Verma, Pawan Tripath, A Digital Security System with Door Lock System Using RFID Technology, International Journal of Computer Applications (0975 - 8887) Volume 5- No.11, August 2010. [CrossRef]

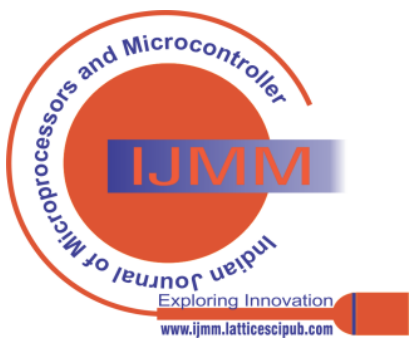




\section{AUTHORS PROFILE}

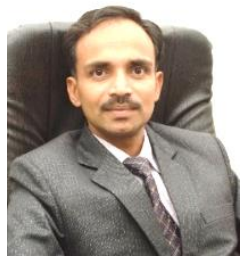

Dr. Akhilesh A. Waoo, Associate Professor and Head, Department of Computer Science \& Engineering AKS University, SATNA, M.P., India., Email - akhileshwaoo@gmail.com

Dr. Akhilesh A. Waoo is having 20+ years of academic and research experience. His qualification includes Doctorate from MANIT (Bhopal), UGCNET, M. Tech. (CSE), RHCSA along with IITBombay (RCC), Virtual Lab, and SWAYAM/MOOC coordinator. Academic Experience is flourished with the organization and coordination of national and international events/workshops/seminars. He had published around 80 research papers in international journals with Computer Networks, Network Security AI, IoT as a major area of interest. He is awarded as Best Faculty. He had published a book on the C\# along with chapters in various books. He is a member of Easy chair. He chairs international conferences and he is a member of the Program Committee of International Conference. His research contribution includes the supervision of a Ph.D. / M. Tech. students along with more than 100 dissertations at UG and PG level of students. Also, he is recognized as a reviewer in many international journals. He is a member of the Computer Society of India (CSI) and the International Association of Engineers (IAENG), Hong Kong.

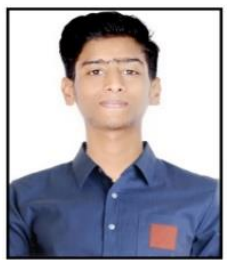

Shubham Soni, is studying B. Tech. in Computer Science and Engineering from AKS University, SATNA, M.P. He is a student of 5th Semester, make IoT based project. He has expertise in Microcontroller and Android Programming domain. He has a lot of interest in IoT. He has designed several IoT and Android-based projects. In which RFID-based door lock system is one of them. This RFID-based door lock system can be unlocked only by the registered person. There are many such projects designed by Shubham Soni, such as passwordbased door lock system, fire and smoke alert and Real-time data on the cloud, etc.

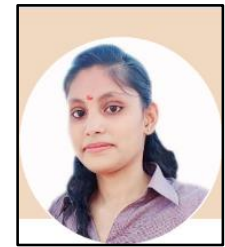

Rajni Soni, is studying in B. Tech. in Computer Science and Engineering from AKS University, SATNA, M.P. She is a student of 5th Semester. She made IOT based project. She knows microcontroller programming as her hobby. She has a lot of interest in the IoT area, due to which she made many IoT projects. In which RFID-based door lock system has been made, which can be unlocked only by the registered person.

There are other such projects which she has made such as a password-based door lock system, fire and smoke alert and real-time data on the cloud, etc.

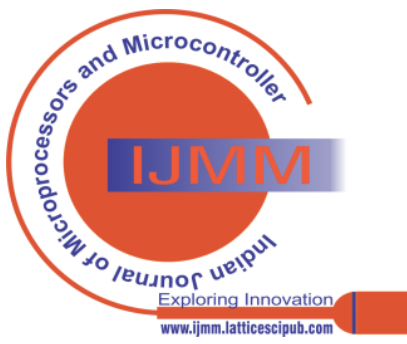

